\title{
EL DERECHO Y LOS JUECES EN LA ESPAÑA DE CERVANTES
}

\section{INTRODUCCIÓN}

Las experiencias profesionales de Cervantes en el sector de actividades económicas, tanto públicas como privadas, que desempeñó en las dos últimas décadas del siglo XVI, le hicieron conocer directa y forzosamente la legislación vigente en la sociedad española de su tiempo y le permitieron valorar su aplicación por las autoridades y los Jueces.

Sus excomuniones y encarcelamientos, sus cargos u "oficios» públicos y negocios privados, los embargos y contratos que suscribió, los apoderamientos ${ }^{1}$, las garantías contractuales prestadas y recibidas ante Escribano, las relaciones de cuentas que formalizó ante la Contaduría de Hacienda y los expedientes administrativos correspondientes, las demandas, recursos y apelaciones que presentó ante los Jueces y los Consejos, etc., etc., son actuaciones reveladoras de las experiencias jurídicas y de la participación de Miguel de Cervantes en el mundo del Derecho y de la Administración pública y judicial de aquella sociedad.

$\mathrm{Y}$ consecuentemente, estas vivencias y los conocimientos adquiridos por nuestro genial escritor y humanista, aparecen nítidamente en sus obras publicadas a partir del año 1.600, concretamente en algunas de sus Novelas Ejemplares y en Los trabajos de Persiles y Segismunda, pero sobre todo en el Quijote de la Mancha, al que

1 Por ejemplo, el poder que prestó Cervantes a su esposa, que consta en el Cap. XLV de la Vida ejemplar y heroica de Miguel de Cervantes Saavedra de AsTRANA MARín, en su tomo IV, de la edición de Editoral Reus, 1952. 
me voy a referir prioritariamente en esta Comunicación que estructuraré en tres partes.

La primera, dedicada a las referencias cervantinas a las Normas Públicas y Privadas y a las relaciones jurídicas en la sociedad de la época. La segunda, a la Administración de la Justicia, sus problemas y a la necesidad de su reforma. Y la tercera, a las Críticas cervantinas al respecto, concluyendo con unas lógicas reflexiones y valoración de la aportación de Cervantes en estas materias, cuya filosofía, según la afirmación de Francisco Giner de los Rios, que comparto plenamente, «es relativa a la reforma del ideal de la vida y de la restauración del Derecho y la Justicia ${ }^{2}$ ». Por supuesto, entrecomillaré en adelante las citas cervantinas.

\section{Las Normas Públicas y PRIVAdas en la España de Cervantes}

El derecho privado y su ejercicio ciudadano y práctica social, es numerosamente citado por Cervantes en relación a casi todos los conceptos jurídicos básicos como vamos a ver a continuación. Habla, por ejemplo, de la necesaria mayoría de edad para ejercer algunos derechos y tomar determinadas decisiones, cuando afirma que «estáis ya en edad de tomar estado o a lo menos, de elegir ejercicio, tal que cuando mayores, os honre y proveche» y que "eran tres, todos varones y todos en edad de poder elegir estado ${ }^{3}$. . Y en el otro extremo de la vida, hay múltiples referencias a la última voluntad, como cuando dice que «te he señalado a tí en el Testamento cerrado que dejé en mi casa ${ }^{4}$ y cuando se refiere al «Testamento con su Codicilo ${ }^{5}$ " que formalizó "ante Escribano» nombrando "Albaceas», o cuando cita las herencias y mayorazgos ${ }^{6}$.

Y en el ámbito de Derecho privado y civil, hay también numerosas referencias a las «dotes» y los compromisos matrimoniales, al necesario "consentimiento ${ }^{7}$ » de las jóvenes y al cumplimiento, incluso por vía judicial, de la promesa de matrimonio, como por ejemplo se deriva de «una cédula que de ser mi esposa la infanta

${ }^{2}$ Estudios de Literatura y Arte, publicados en 1919 y que constan en el tomo III de las Obras Completas de FRANCISCO GINER DE LOS Ríos, en sus comentarios sobre las obras de Nicolás Díaz de Benjumea y Francisco Tubino.

3 Don Quijote, P. 1, Cap.39, de la edición de LuIS ANDRÉS Murillo, de Editorial Castalia de 1982, texto al que se refieren el resto de las notas citadas en mi escrito, que constan en El Ingenioso Hidalgo Don Quijote de la Mancha referido. Y ello, en su Parte primera (P. 1) y segunda (P. 2).

${ }_{4}$ Don Quijote, P. 1, Cap. 20.

5 Don Quijote, P. 2, Cap.7 y Cap. 74.

Don Quijote, P. 1, Cap. 12

7 Don Quijote, P. 1, Cap. 12. 
le habría hecho ${ }^{8}$ ». Y en este ámbito matrimonial, hay una genial referencia al posible carácter temporal del matrimonio, ya que los esposos "quedaron en disoluble vínculo ligados ${ }^{9}$ ", y otra a la rechazable situación subordinada de la esposa a su marido en aquella época todavía machista, en la que las mujeres tenían legalmente que «estar obedientes a sus maridos aunque sean unos porros ${ }^{10}$ ». Y en este ámbito conceptual, fue el autor de un título significativo y plenamente original entonces, cual es el del entremés «El Juez de los Divorcios».

Y en este mismo campo del Derecho Privado, hay diversas referencias en el Quijote de la Mancha y en las Novelas Ejemplares a los contratos de compraventa y de las Ferias, a la «barata», a los «préstamos», las "garantías» y «fianzas», a la existencia de «arrendamientos» y del «alquiler», a las «libranzas» de pago y a las «cédulas de cambio» y de "recibo» como documentos formalizados y a los «daños», «perjuicios», «menoscabos», e «intereses», en "perjuicio de tercero». Y una sutil afirmación jurídica cuando se refiere a la adquisición de la propiedad a través de la aparente posesión de buena fé cuando decide Sancho Panza "poseerlo yo de buena fé hasta que ...pareciera su verdadero señor... y entonces el Rey me haría franco ${ }^{11}$ ».

Todos estos vocablos jurídicos, que hoy son ya clásicos y muy conocidos, eran entonces menos usados en la literatura de la época, aunque constan en los escritos profesionales de aquella sociedad y en muchos de los documentos archivados de la época y debidamente definidos en las leyes y Ordenanzas de los siglos XVI y XVII, como lo pone de relieve, por ejemplo, la «Pragmática de los Contratos» publicada en 1573.

Asimismo, Cervantes se refiere, además de al Derecho Privado y a su ejercicio por los ciudadanos, al Derecho Público, a la «Razón de Estado y modos de gobierno ${ }^{12}$ », a las Leyes y las Pragmáticas, a las normas que «tasan» y limitan los «salarios» y los precios, a la libertad y regulación de "la impresión y edición» y de la representación escénica de las obras literarias «en las repúblicas bien concertadas ${ }^{13}$ ", así como a las tarifas y aranceles de aduanas o "almojarifazgos» y registros de las mercancías y monedas que cruzan

8 Don Quijote, P. 2, Cap.38, y Las dos doncellas. En este caso de Las dos doncellas, como en el de las demás citas de las Novelas ejemplares, he utilizado la edición de José Ibañez Campos, realizada por Edicomunicación, S. A., en 1994.

9 Don Quijote, P. 1, Cap. 27.

10 Don Quijote, P. 2, Cap. 5.

1 Don Quijote, P. 1, Cap. 23.

12 Don Quijote, P. 2, Cap. 1.

13 Don Quijote, P. 1, Cap.32. 
las fronteras nacionales, como se afirma en Rinconete y Cortadillo y en el Quijote.

También escribe sobre la política interior, de seguridad y de defensa y a sus normas, cuando afirma Don Quijote que las armas «tienen por objeto y fin la paz, que es el mayor bien que los hombres pueden desear en esta vida ${ }^{14}$ ». Y que "con las armas se defienden las repúblicas, se conservan los reinos, se guardan las ciudades, se aseguran los caminos, se despejan los mares de corsarios... ${ }^{15}$ ». Y concreta y declara, como si fuera un jurisperito y caballero andante, que "sin las letras no se podrían sustentar las armas, porque la guerra también tiene sus leyes y está sujeta a ellas y que las leyes caen debajo de lo que son las letras y letrados ${ }^{16}$ ».

Respecto a las leyes y al Derecho Publico, insiste repetidas veces Cervantes en que los legisladores no deben hacer leyes solamente por hacerlas sino procurar que «sean buenas y sobre todo que se guarden y cumplan», ya que «las pragmáticas que no se guardan, lo mismo es que si no fuesen ${ }^{17}$ ». Pero está de acuerdo en la necesidad de renovación de las leyes en aquel momento clave del Renacimiento y la Modernidad, al afirmar que "hoy se hace una ley y mañana se rompe y quizá conviene que así sea ${ }^{18}$ ".

$\mathrm{Y}$ todo ello era y es tan importante que, como muchos ciudadanos, los amigos del Quijote se reunieron para «tratar en esto que llaman la razón de Estado y modos de gobierno...haciéndose cada uno de los tres un nuevo legislador... y de tal manera, renovaron la república ${ }^{19}{ }$; superando así la habitual concepción de la "Razón de Estado, que cuando con ella se cumple, se ha de descumplir con otras razones muchas ${ }^{20}$ ».

Había muchas definiciones contemporáneas de estos conceptos y afirmaciones cervantistas, a su favor o con diferencias, pero que ponen de relieve su cultura de cuasi-jurista y la razonabilidad de sus textos, tal y como consta en las pragmáticas y Ordenanzas de la época, que constan especialmente en la Recopilación de Leyes hecha por Felipe II e impresa en Alcalá de Henares en 1569 y que se publica de nuevo y actualiza en 1581 , en 1592 y $1598^{21}$.

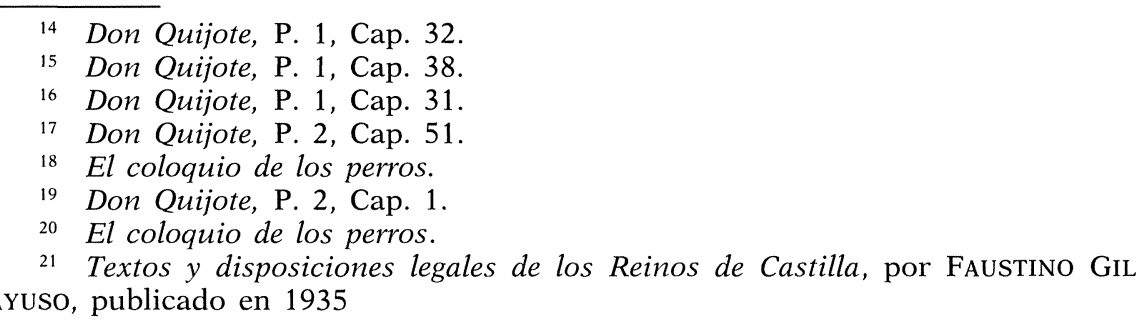




\section{La Administración de la Justicia EN LA Sociedad de CERVANTES}

Cervantes parte, en sus referencias y comentarios sobre esta cuestión, de la convicción de que existe «la necesidad de valerse de la Justicia ${ }^{22}$ ", por lo que a "Administrar justicia ha de atender el Señor del Estado ${ }^{23}$ ".

Y, precisamente por ello, hay en el Quijote y en las Novelas Ejemplares, múltiples referencias al sistema judicial y al procesal. Nos describe su estructura organizativa, citando a los «Jueces», los «Oidores», los «Escribanos», los «Gobernadores» y «Asistentes» como los directos y principales miembros del Poder Judicial, en el que, como sabemos, no existía todavía la división e independencia de los poderes ejecutivo y judicial, pero en cambio, como nos informa Cervantes también, ya existía la posibilidad de Apelación ante las «Audiencias», los «Tribunales», los «Consejos» y las «Chancillerías», que ponían las sentencias en «su punto y rigurosa y debida proporción ${ }^{24}$ ». Y, por el contrario, la gran amenaza e injusticia prácticamente sin defensa o solución posible, era la denuncia al Santo Oficio, lo que uno de sus personajes resalta cuando dice «conténtate que no te acuso a la Inquisición ${ }^{25}$ ».

Cita también Cervantes a los que llama, con el lenguaje oficial de la época, "Ministros» y "Miembros de la Justicia», como son por un lado los «alguaciles», los "cuadrilleros de la Santa Hermandad ${ }^{26}$ ", los «corchetes y los verdugos»; y por el otro, a los "procuradores, solicitadores, abogados y letrados». Los primeros intervienen en los «mandamientos de prisión ${ }^{27}$ » y ejecución de las penas impuestas a los delincuentes y los segundos en las «causas», "pleitos» y «querellas» que se realizan en el ámbito de la «jurisdicción ${ }^{28}$ » correspondiente.

Habla también de «delitos» y "penas», de los «homicidas», de la cárcel y de «la prisión, de la pena del destierro», de las penas de contenido económico, de la «condena en costas», de la «horca» y la pena de muerte y también de la «muerte civil» como pena impuesta a ciertos «delincuentes ${ }^{29}$ ».

22 El casamiento engañoso.

23 Don Quijote, P. 1, Cap. 50.

24 El licenciado Vidriera.

25 La ilustre fregona.

Don Quijote, P. 1, Caps. 16 y 45.

Don Quijote, P. 1, Cap. 45.

El licenciado Vidriera, Rinconete y Cortadillo y La ilustre fregona.

29 Don Quijote, P. 1, Cap. 22 y P. 2; Caps. 26 y 54. El celoso extremeño y La ilustre fregona. 
Y además de estas referencias que nos descubren una parte esencial de la estructura judicial de la época, hay afirmaciones cervantistas tan sugerentes como cuando escribe que "hay que buscar al Juez para que ejecutase la pronunciada sentencia ${ }^{30}$ » y que, posteriormente, determinadas actuaciones, como las «sentencias firmes», hay que darlas "por vistas y por pasadas en cosa juzgada ${ }^{31}$ ». $\mathrm{Y}$ en relación a los pleitos y procesos judiciales, hace también referencias a los «demandantes», las "pruebas» y «repruebas ${ }^{32}$ » de los letrados y procuradores, a los «contenidos» y «demandados», a los «Autos» y declaraciones judiciales en los pleitos, que deben «dar traslado a la parte»; y a la posibilidad de «que haya apelación de su sentencia para otro Tribunal».

En los pleitos y querellas, señala como defensores a los «letrados» y «procuradores» que utilizan las «declaraciones de los testigos», apoyándose también en los «Escribanos» y hace también Cervantes mención al deudor que en el pleito "reconoció su firma y confesó la deuda» y a que «querellóse el dueño, hubo pruebas y repruebas y fueron las que hizo el dueño tan buenas que salió la sentencia su favor ${ }^{33}$ ", aunque también señaló Cervantes que a veces esto es debido «merced a testigos falsos ${ }^{34}$ ».

La unificación existente entonces de los poderes judicial y ejecutivo, se refleja en el doble y unitario grito de «Téngase a la Justicia!» y «Téngase a la Santa Hermandad! ${ }^{35}$ », pero lo que Cervantes analiza y critica rigurosamente son las injusticias y la corrupción que había con cierta frecuencia en aquella «depravada edad nuestra», por lo que se necesitaba que «la justicia de Dios y del Rey venga ${ }^{36}$ ".

En este mismo sentido, hay también algunos textos cervantinos que nos hablan positivamente de la existencia de un sistema de control obligatorio y general de las actividades y decisiones de los Jueces y los Gobernadores, control denominado entonces «Acto de Residencia ${ }^{37}$ », en el que éstos debían dar cuenta de sus actividades, decisiones y sentencias al Rey y a sus Consejos, como hoy se haría ante Auditores, Interventores y Abogados del Estado ó ante el Tribunal de Cuentas. Pero pese a la existencia del control legal a través de la Residencia, afirma irónica e intencionadamente un

30 Don Quijote, P. 1, Cap. 4.

31 Don Quijote, P. 1, Caps. 27 y 30.

32 Don Quijote, P. 2, Caps. 26, 42 y 45.

Rinconete y Cortadillo.

${ }^{3}$ Rinconete y Cortadillo.

Don Quijote, P. 1, Cap. 16.

Rinconete y Cortadillo.

Don Quijote, P. 2, Caps. 42 y 52. 
personaje cervantista que «coheche señor teniente, coheche y tendrá dineros...que de los oficios se ha de sacar dineros para pagar las condenaciones de las Residencias y para pretender otros cargos ${ }^{38}$ ».

\section{Las CRíticas de Cervantes a la Administración de la Justicia}

Hay unas contundentes críticas de nuestro genial escritor y humanista auténtico, a determinadas actuaciones judiciales cuando Don Quijote dice, comparando la Justicia de su época con la que había existido anteriormente, que, antes, "la Justicia se estaba en sus propios términos, sin que la osasen turbar ni ofender los del favor y los del interese, que tanto ahora los menoscaban, turban y persiguen. La ley del encaje aún no se había sentado en el entendimiento del Juez ${ }^{39}$ ".

Pero también da importancia y una valoración positiva a las actuaciones judiciales, a las normas del Derecho Público y a la Razón de Estado, cuando dice Cervantes que «hablo de las letras humanas, que es su fin poner en su punto la justicia distributiva y dar a cada uno lo que es suyo, entender y hacer que las buenas leyes se guarden ${ }^{40}$ ». $\mathrm{O}$, cuando afirma, con ironía, que «finalmente ellos, como miembros de la justicia, mediaron la causa y fueron árbitros della ${ }^{41}$ ».

Puso de relieve también Cervantes la existencia del «fraude»y del «cohecho», la codicia de los gobernadores y de los jueces, afirmando que «no hay ningún género de oficio destos de mayor cuantía que no se granjee con alguna suerte de cohecho, cual más, cual menos ${ }^{42}$ ».

Y opina que «la codicia rompe el saco y el gobernador codicioso, hace la justicia desgobernada ${ }^{43}$ ». Y que por ello, «siempre los ricos que dan en liberales, hallan quien canonice sus desafueros ${ }^{44}$ », porque «no les falta ungüento para untar a todos los ministros de Justicia ${ }^{45}$ ».

Insiste en la necesidad de que «los jueces y gobernadores deben ser ó han de ser de bronce... sin perdonar derecho ni llevar cohecho ${ }^{46}$ ", para que no se repita, y lo cita como ejemplo vivido perso-

\footnotetext{
38 La gitanilla.

39 Don Quijote, P. 1, Cap. 1,1.

Don Quijote, P. 1, Cap. 37.

Don Quijote, P. 1, Cap. 46.

Don Quijote, P. 2, Cap. 41

Don Quijote, P. 2, Cap. 36.

4 Rinconete y Cortadillo y La fuerza de la sangre.

Rinconete y Cortadillo y La fuerza de la sangre.

46 Don Quijote, P. 2 Cap. 49.
} 
nalmente, "cuan descuidada justicia había en aquella tan famosa ciudad de Sevilla ${ }^{47}$ »; y para luchar contra «la gente ancha de conciencia y desalmada sin temer al Rey ni a su Justicia ${ }^{48}$.

Su experiencia vital le confirma a Cervantes que «no es menester ni mucha habilidad ni muchas letras para ser un gobernador, pues hay ciertos que apenas saben leer y gobiernan como gerifaltes", aunque hay también "gobernadores caballeros y no letrados que sentencian con asesor ${ }^{49}$ ".

Y esta descripción crítica de la estructura y funcionamiento de la Administración Judicial y Pública de la sociedad de su tiempo, tenía su origen, tanto en España como en el resto de las «naciones políticas» europeas y mediterráneas, en la problemática y potencialidad generada por la transición del Bajo Medioevo y del Renacimiento hacia el Estado Moderno cuya estructuración inicial vivió Cervantes y condicionó sus actividades y experiencias personales.

Estas críticas cervantinas a la Administración judicial de aquella sociedad, están por ello relacionadas en Cervantes con sus vitales experiencias y consecuente opinión sobre el funcionamiento de la Corte (o Administración Central de la época), y de algunos Palacios en los que " más medran los truhanes que los discretos ${ }^{50}$ » $\mathrm{y}$ que «alargan las esperanzas de los atrevidos pretendientes» y acortan «las de los virtuosos encogidos ${ }^{51}$ », por lo que en la Corte o Administración Central, se va a negociar asuntos a través «del favor y de las dádivas ${ }^{52}$ », con lo que consiguen «muchas cosas dificultosas» ó injustas. Por ello afirma Don Quijote que " si a los oídos de los príncipes llegase la verdad desnuda, sin los vertidos de la lisonja, otros siglos correrían ${ }^{53}$ ». Y afirma por ello valerosamente que "la verdadera nobleza consiste en la virtud ${ }^{54}$ ».

También responsabiliza a algunos de los arbitristas de la época, afirmando Don Quijote que «todos o los más arbitrios que se dan a Su Majestad o son imposibles o disparatados, o en daño del Rey o del Reino ${ }^{55}$ \%. Aunque como latente arbitrista, no económico sino social y democrático, recuerda al Rey y a los dirigentes que "para ganar la voluntad del pueblo que gobiernas, entre otras cosas...has

\footnotetext{
47 Rinconete y Cortadillo.

48 El coloquio de los perros.

Don Quijote, P. 2, Cap. 32.

La gitanilla.

El licenciado Vidriera.

Don Quijote, P. 2, Cap. 65

Don Quijote, P. 2, Cap. 2.

Don Quijote, P. 1, Cap. 36

Don Quijote, P. 2, Cap. 1
} 
de procurar la abundancia de los mantenimientos, que no hay cosa que más fatigue el corazón de los pobres que la hambre y la carestía ${ }^{56}$ ".

Pero estas críticas cervantinas no quiere generalizarlas ni homologarlas con las opiniones de los delincuentes y de determinados ciudadanos que conoce, que eran «maldicentes» y que "comienzan a mostrar la malignidad de sus lenguas»...»por decir mal de los escribanos y alguaciles y de los Ministros de la Justicia... ${ }^{57}$ »

Y se refiere positivamente a los escribanos, sin cuyo oficio (también de fé pública notarial), «andaría la verdad por el mundo a sombra de tejados, corrida y maltratada; es el escribano persona pública, y el oficio del Juez no se puede ejercitar cómodamente sin el suyo ${ }^{58}$ ». Por cierto que hay una referencia «a más de veinte mil escribanos que hay en España», y a que es «la gente más necesaria que había en las repúblicas bien ordenadas ${ }^{59}$ », afirmando también en el Apoderamiento antes citado que «os podéis concertar y dejar en manos de jueces árbitros que lo vean, sentencien y determinen por justicia o amigablemente ${ }^{60} \%$.

\section{CONCLUSIONES}

Cervantes, como hemos visto, nos pone al día de las principales cuestiones, conceptos y problemas que definen el funcionamiento del Derecho y de los Jueces en la España que vivió, principalmente la del cruce de los siglos XVI y XVII; en el cual, su vida profesional participó de alguna de las experiencias propias que hubiera tenido, como letrado, su «Licenciado Vidriera», «cuyo principal estudio fué de las leyes, pero en lo que más se mostraba era en letras huma-

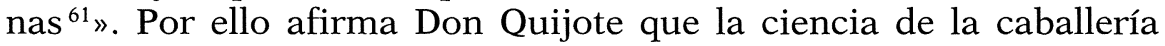
andante " es una ciencia que encierra en sí todas las más ciencias del mundo, a causa de que el que la profesa ha de ser jurisperito, y saber las leyes de la justicia distributiva y conmutativa, para dar a cada uno lo suyo y lo que le conviene ${ }^{62}$ ».

$\mathrm{Y}$, como humanista profundo que era vitalmente y caballero andante y jurisperito que era moralmente, Miguel de Cervantes señala, junto a la Justicia, como objetivo personal y social, a la Igual-

\footnotetext{
Don Quijote, P. 2, Cap. 51

El licenciado Vidriera.

El licenciado Vidriera

El licenciado Vidriera.

Astrana Marín, Cap. XLV.

El licenciado Vidriera.

Don Quijote, P. 2, Cap. 18.
} 
dad y a la Libertad. En relación a la Igualdad, Don Quijote dice que de la caballería andante «se puede decir lo mismo que del amor se dice: que todas las cosas iguala ${ }^{63}$ ». Y, como la esencia vital de su personalidad es el amor por la Libertad, Don Quijote nos confirma que «uno de los más preciosos dones que a los hombres dieron los cielos es la Libertad; con ella no pueden igualarse los tesoros que encierra la tierra ni el mar encubre; por la libertad, así como por la honra, se puede y debe aventurar la vida ${ }^{64}$ ».

Espero que mi comunicación haya puesto de relieve, con las correspondientes citas cervantinas, que en las obras de Miguel de Cervantes hay múltiples y acertadas referencias al Derecho y a los Jueces de la sociedad española de su tiempo, en la cual, como dice Don Quijote a Sancho Panza, "su escudero fiel y legal», hay que " descubrir la verdad» $\mathrm{y}$ " tener lugar la equidad ${ }^{65}$ ». El papel de los jueces y de los letrados y la justa aplicación de las leyes a la economía y a las relaciones sociales y contractuales por su parte y por los políticos y administradores públicos, fue subrayado repetidas veces por Cervantes "para poner en su punto la justicia distributiva y dar a cada uno lo que es suyo ${ }^{6 \%}$.

Todo ello nos confirma, una vez más, que la lectura del Quijote de la Mancha no solo emociona nuestro corazón y enriquece nuestra mente, sino que nos facilita una amplia y realista información sobre la sociedad existente en un momento clave y de transición de la historia, la economía, el derecho, la estructura social y del Estado y la cultura de España, información realista pero vista y escrita desde la perspectiva quijotesca del idealismo humanista de Cervantes.

LUIS LARROQUe ALLENDE

Instituto Universitario Ortega y Gasset

${ }_{63}$ Don Quijote, P. 1, Cap. 11.
${ }_{64}$ Don Quijote, P. 2, Cap. 58.
${ }_{65}$ Don Quijote, P. 2, Cap. 42.
${ }_{6}$
Don Quijote, P. 1, Cap. 37. 